\title{
Ultrasonographic Diagnosis of A2 or A4 Flexor Tendon Pulley Injury: A Systematic Review
}

\author{
Xeber Iruretagoiena-Urbieta, $\mathrm{PT}, \mathrm{MSc}^{1,2}$; Javier De la Fuente-Ortiz de Zarate, MD, $\mathrm{PhD}^{3}$; \\ Elena Sonsoles Rodríguez-López, PT, DO, $\mathrm{PhD}^{1}$; Pablo Barceló-Galíndez, $\mathrm{MD}^{4}$; \\ Ángel Oliva-Pascual-Vaca, PT, DO, $\mathrm{PhD}^{5}$; Álvaro Otero-Campos, $\mathrm{PT}^{1}$; Marc Blasi, $\mathrm{MD}^{6}$ \\ ${ }^{1}$ Department of Physiotherapy, Universidad Camilo José Cela, Madrid, Spain; ${ }^{2}$ Eskura Osasun Zentroa, Beasain, Spain; ${ }^{3}$ Orthopedics Department, \\ Clínica Pakea-Mutualia, San Sebastián, Spain; ${ }^{4}$ Ultrasonography Department, Clínica Ercilla-Mutualia, Bilbao, Spain; ${ }^{5}$ Department of Physiotherapy, \\ Universidad de Sevilla, Seville, Spain; ${ }^{6}$ Department of Plastic Surgery, Hospital Germans Trias i Pujol, Badalona (Barcelona), Spain
}

\begin{abstract}
A2 or A4 annular finger pulley tears are common injuries in rock climbers. This study reviews the measurement procedures used and tendon-to-bone distance data obtained on high-resolution ultrasound images when diagnosing isolated rupture of the A2 or A4 pulleys. Out of 3447 records extracted, only 7 remained after applying the exclusion criteria. In diagnosing a complete rupture, tendon-to-bone distance used varied widely from 1.9 to $5.1 \mathrm{~mm}$ for A2 and from 1.8 to $3.1 \mathrm{~mm}$ for A4. Our findings point to a lack of consensus diagnostic criteria for pulley injuries and identify technical details needing further research.
\end{abstract}

Keywords: annular pulley, ultrasonography, ultrasound, tendon-bone distance, rupture

\section{Introduction}

Rock climbing has evolved from explorers attempting to cross or climb mountains in the wilderness to a high-performance athletic sport. ${ }^{1}$ Today's new modalities of climbing being conducted in controlled environments means that modern climbers are able to perform at a much higher level and much younger age. ${ }^{2}$ Rock climbing has even been recognized as an official Olympic sport, set to debut in the 2020 Tokyo Olympics. $^{3}$ According to the Spanish Sports Council, rock climbing and mountaineering now have the fifth greatest number of registered athletes among all sports, having risen from 65,285 participants in 2001 to 237,825 in $2017 .{ }^{4}$

As rock climbing gains popularity, injuries related to its specific technical movements and hand grips have also prompted interest in both the health and basic science fields. Among all injuries sustained by rock climbers, finger pulley injuries account for $33 \%$; the ring finger is especially affected, followed by the middle finger. ${ }^{5}$

Corresponding author: Elena Sonsoles Rodríguez-López, PT, DO, PhD, Department of Physical Therapy, Camilo José Cela University, Urb. Villafranca del Castillo, C/ Castillo de Alarcón, 49, 28692 Villanueva de la Cañada, Madrid, Spain; e-mail: esrodriguez@ucjc.edu.

Submitted for publication November 2019.

Accepted for publication July 2020.
The digital flexor pulley system is composed of 5 annu$\operatorname{lar}(\mathrm{A} 1-\mathrm{A} 5)$ and 3 cruciate pulleys $(\mathrm{C} 1-\mathrm{C} 3)$. Their primary role is to hold the flexor tendon close to the phalanx, allowing conversion of the tendon excursion force into an adequate finger flexion motion pattern. ${ }^{5}$ Pulleys can be partially or completely ruptured, affecting a single pulley or multiple pulleys at the same time. The A2, the longest and the most consistent pulley, has the highest injury rate, followed by A4. ${ }^{6}$ These injuries must be carefully identified and managed; otherwise, they can lead to definitive loss of interphalangeal joint flexion and osteoarthritis. $^{7}$

High-resolution ultrasound imaging (US) is considered the reference standard for the diagnosis of annular finger pulley injuries owing to its low cost compared to other imaging techniques, its noninvasive nature, the availability of handheld portable devices, and its dynamic assessment capacity. ${ }^{8,9}$ Tendon-to-bone distance (TBD) is an indirect measure used by ultrasonographers to diagnose a pulley tear (Figure 1). To date, however, there is no consensus as to the best measurement protocols or specific TBD reference values for a diagnosis of a pulley injury. ${ }^{8-14}$

In this study, we systematically reviewed all reports of studies addressing the US diagnosis of isolated A2 or A4 pulley tears with the following objectives: 1) to analyze the details of US assessment protocols available in the 

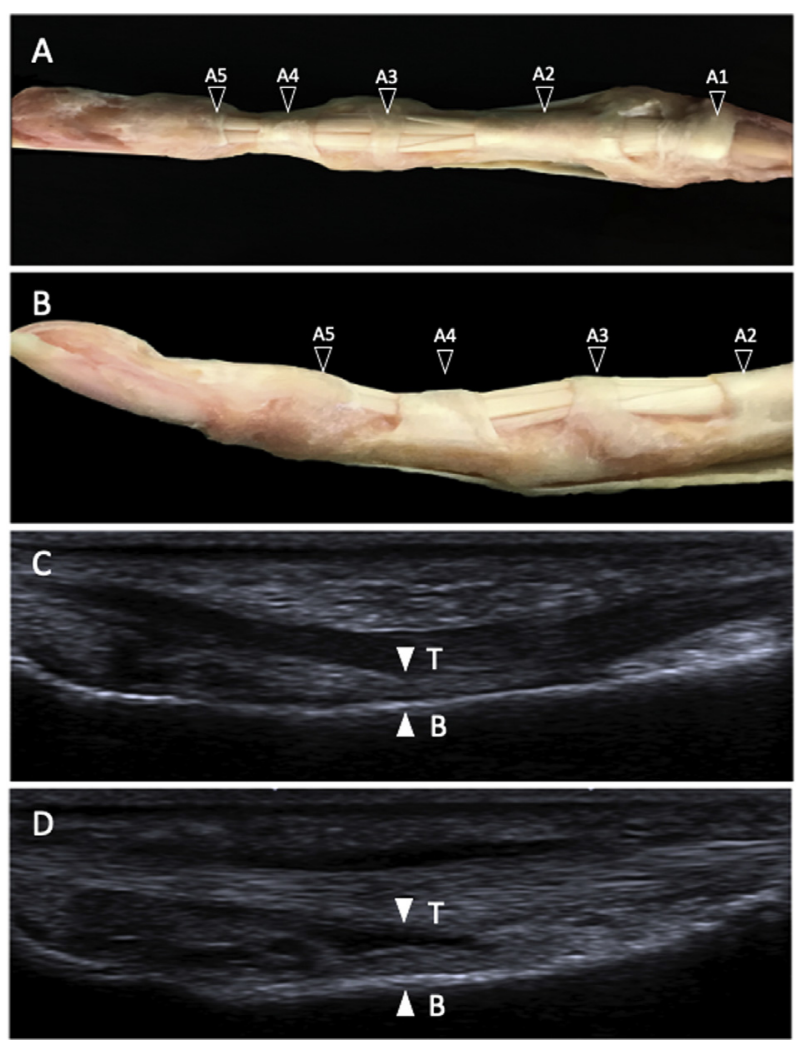

Figure 1. Comparison of the anatomic and ultrasound findings of digital annular pulley system. (A, B) Cadaveric annular pulleys (black arrowheads) in palmar and lateral view. C, Ultrasound view in long axis palmar approach of a nonruptured A4 annular pulley; tendon (T, flexor digitorum profundus) to bone ( $\mathrm{B}$, middle phalanx) distance of $1.1 \mathrm{~mm}$ (white arrowheads) in active forced flexion finger position. D, Ultrasound view in long axis palmar approach of a complete ruptured A4 annular pulley, tendon to bone distance of $2.3 \mathrm{~mm}$ (white arrowheads) in active forced flexion finger position.

literature, including transducer characteristics, transmission surface type (coupling agents), patient finger position, anatomic landmarks for measurements, the force applied by the patient to activate the finger, and the opposing resistance provided by the examiner; and 2) to establish the minimum TBD used to diagnose complete and partial ruptures of the A2 or A4 pulleys.

\section{Methods}

\section{SEARCH STRATEGY}

This review was conducted according to preferred reporting items for systematic reviews and meta-analyses guidelines. ${ }^{15}$

The databases PubMed, Scopus, Web of Science, and ScienceDirect were searched for studies addressing the US diagnosis of A2 and A4 pulley injuries. The search terms used along with the Boolean operator "AND" were as follows: pulley, ultrasound, sonography, and diagnosis. The records extracted from each database using a combination of these terms are provided in Table 1 . The references found in most of the studies identified were also screened for publications that could be of interest for the present review. All searches were conducted over the period of September to November 2018 by 3 independent investigators (XIU, ESRL, JDLF).

\section{STUDY SELECTION}

All titles and abstracts were considered for inclusion according to the following criteria: 1) US diagnostic studies providing TBD data; 2) studies addressing the A2 and/or A4 finger pulleys; 3) descriptive studies, reviews, and meta-analyses; and 4) reports written in English or Spanish.

Exclusion criteria were as follows: 1) studies assessing conservative treatment; 2 ) studies addressing invasive treatments such as surgery or infiltration therapy; 3 ) studies focusing on the thumb or toes; 4) studies in children; 5) studies in animals; 6) studies centering on the A1 or A3 finger pulley; 7) studies on basic anatomy or rheumatic diseases of the fingers; 8) studies using color Doppler US; 9) studies about diseases or surgery not involving the fingers; 10) studies not focusing on medical issues; 11) case reports, pilot studies, meeting proceedings, and book chapters; and 12) studies published in a language other than English or Spanish.

\section{DATA COMPILATION AND EXTRACTION}

Our main objective was to address the US diagnosis of A2 and A4 finger pulley injuries. Once all illegible studies had been identified, the remaining records were analyzed according to sample size and type, diagnostic method, finger position and active forced flexion versus passive mobilization during US measurements, anatomical landmark for measuring pulley TBD, and TBD measurements.

\section{STUDY QUALITY}

To assess the methodological quality of the descriptive studies, the validated critical appraisal skills program Español (CASPe) was used. This scale consists of 10 questions designed to assess the validity, quality, and applicability of diagnostic studies. ${ }^{16}$

\section{Results}

\section{STUDY SELECTION}

Of 3447 records extracted, 1174 were excluded because they were duplicates and 1963 on the grounds of their title in relation to the selection criteria. Of 310 articles 
Table 1. Search strategies and records extracted from each database

\begin{tabular}{|c|c|c|c|c|c|c|}
\hline $\operatorname{Search}(n)$ & Search terms & $S$ & $S D$ & $P M$ & WOS & Total \\
\hline 1 & Search ("pulley" AND "ultrasound") & 119 & 1446 & 204 & 151 & 1920 \\
\hline 2 & Search ("pulley" AND “sonography") & 29 & 159 & 101 & 35 & 324 \\
\hline 3 & Search ("pulley" AND "ultrasound" AND “diagnosis") & 35 & 883 & 64 & 60 & 1042 \\
\hline \multirow[t]{2}{*}{4} & Search ("pulley" AND "sonography" AND "diagnosis") & 8 & 128 & 10 & 15 & 161 \\
\hline & Total for each database & 191 & 2616 & 379 & 261 & 3447 \\
\hline
\end{tabular}

PM, PubMed; S, Scopus; SD, ScienceDirect; WOS, Web of Science.

remaining, 277 were rejected according to the exclusion criteria after reading their abstracts.

The full texts of the 33 remaining studies were examined and 26 were excluded because, despite focusing on US and/or TBD in A2 and/or A4 pulley ruptures, they were not specific enough to satisfy the study selection criteria: 12 studies were general reviews about rockclimbing injuries, 1 study was about US tendon bowstringing (an excessive separation of the flexor tendon from the center of rotation of the proximal interphalangeal joint) at the proximal phalanx without TBD measurements, 2 studies were about US adaptive pulley changes, 2 studies were about TBD measured by magnetic resonance imaging (MRI), 1 study was about US anthropometric measurements in cadaveric and nonpathological volunteers not including TBD measurements, 1 study was about US diagnosis not considering TBD, 1 study was about grip strength measurements in pulley ruptures, 2 studies addressed conservative treatment, and 4 studies were centered on surgical treatment.

A flow diagram showing how the 7 studies finally included $^{8-14}$ were selected is provided in Figure 2. The main characteristics and findings of these studies are provided in Table 2.

The selected studies obtained a mean CASPe score of 7.9 out of 10 , indicating their good methodological quality (Table 3).

\section{STUDY SAMPLE CHARACTERISTICS}

Five of the 7 studies reviewed were performed in rock climbers and included 42 participants 10 to 604 participants. ${ }^{14}$ The other 2 studies were conducted in cadavers and included only 11 hands $^{12}$ and 14 hands $^{9}$ (Table 2).

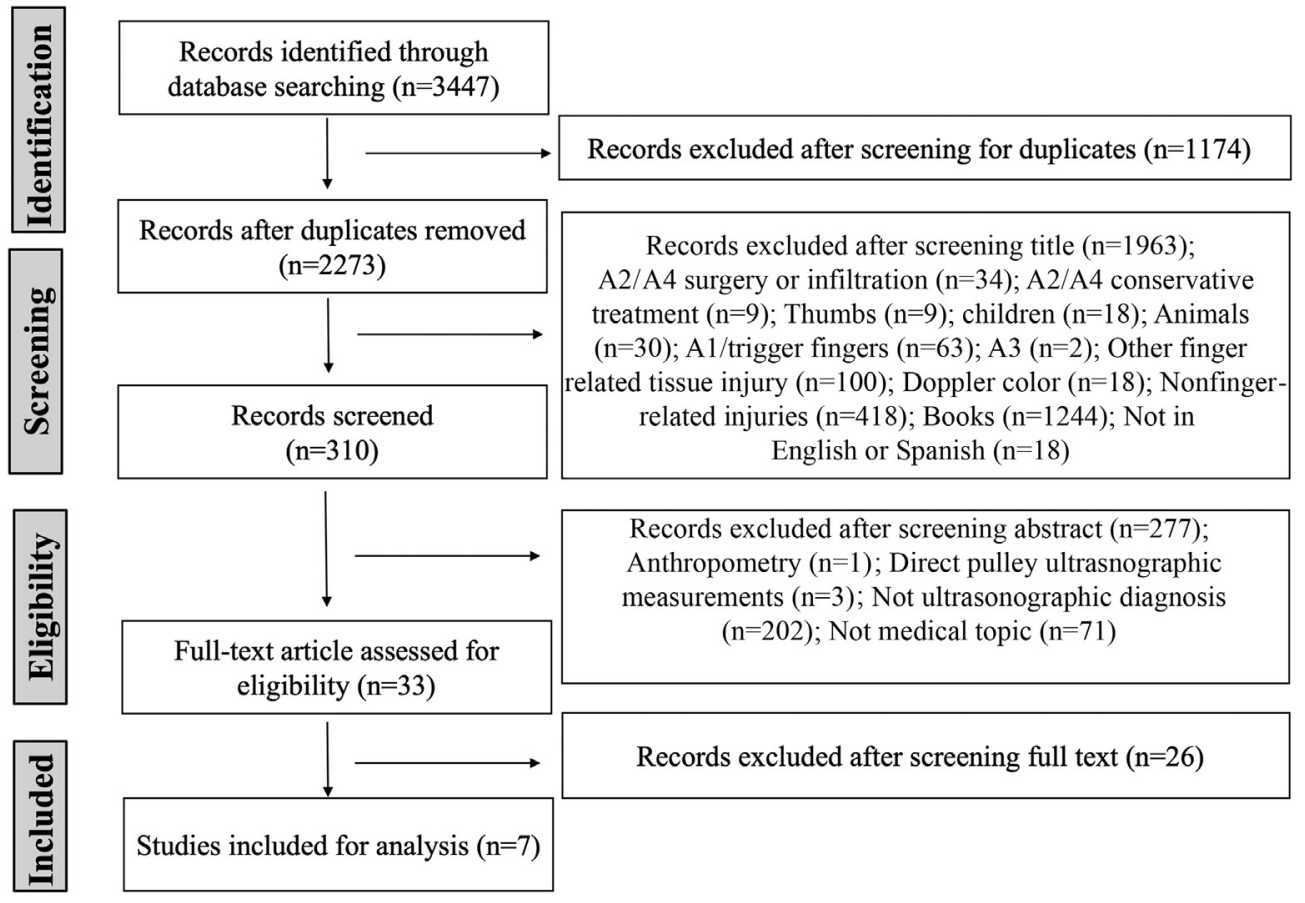

Figure 2. Consolidated standards of reporting trials flow diagram. 
Table 2. Methods and ultrasound results of the studies reviewed

\begin{tabular}{|c|c|c|c|c|c|}
\hline Reference & Sample & Diagnostic method & US finger position & US landmark & $T B D$ mean (range) or mean $\pm S D$ \\
\hline $\begin{array}{l}\text { Bassemir } \\
\text { et al }^{8}\end{array}$ & $\begin{array}{l}200 \text { healthy } \\
\text { nonclimbers }\end{array}$ & $\begin{array}{l}\text { US } 18 \mathrm{MHz} \\
\text { (gel pad) }\end{array}$ & $\begin{array}{l}\text { a) Rest } \\
\text { b) AFF }(500 \mathrm{~g}) \text { : } \\
\text { PIP ext } \\
\text { DIP } 30^{\circ} \text { flex }\end{array}$ & $\begin{array}{l}\text { a) A2: } \\
\text { PT-mid PP } \\
\text { b) A4: } \\
\text { mid MP }\end{array}$ & $\begin{array}{l}\text { a) A2: } \\
\text { Rest: } 0.4(0.3-0.6) \mathrm{mm} \\
\text { AFF: } 0.5(0.3-0.8) \mathrm{mm} \\
\text { b) A4 } \\
\text { Rest: } 1.1(0.6-1.8) \mathrm{mm} \\
\text { AFF: } 1.4(0.8-2.2) \mathrm{mm} \\
\text { (Summarized results from Table } 3)^{8}\end{array}$ \\
\hline $\begin{array}{l}\text { Schöffl } \\
\text { et al }\end{array}$ & $\begin{array}{l}14 \text { cadaver } \\
\text { hands }\end{array}$ & US $14 \mathrm{MHz}$ & $\begin{array}{l}\text { a) AFF }(10 \mathrm{~N}) \text { : } \\
\text { DIP } 30^{\circ} \text { flex }\end{array}$ & & $\begin{array}{l}\text { a) CR A2: } \\
\text { AFF: } 1.9 \mathrm{~mm} \\
\text { b) CR A2 (multiple rupture): } \\
\text { AFF: } 3.7 \mathrm{~mm} \\
\text { c) CR A4: } \\
\text { AFF: } 1.8 \mathrm{~mm} \\
\text { d) CR A4 (multiple rupture): } \\
\text { AFF: } 2.7 \mathrm{~mm}\end{array}$ \\
\hline $\begin{array}{l}\text { Bodner } \\
\text { et al }^{10}\end{array}$ & $\begin{array}{l}32 \text { patients } \\
\text { (29 climbers, } \\
3 \text { nonclimbers) } \\
\text { Control group } \\
\text { (10 nonclimbers) }\end{array}$ & $\begin{array}{l}\text { US } 10 \mathrm{MHz} \\
\text { (silicon-pad) } \\
\text { MRI }\end{array}$ & $\begin{array}{l}\text { a) Rest } \\
\text { b) AFF (max): } \\
\text { MCP } 0^{\circ} \\
\text { PIP } 40^{\circ} \text { flex } \\
\text { DIP } 10^{\circ} \text { flex }\end{array}$ & $\begin{array}{l}\text { a) A2: } \\
\text { DT PP } \\
\text { A2 distal end }\end{array}$ & $\begin{array}{l}\text { a) CR A2: } \\
\text { Rest: } 3.1(3.1-4.5) \mathrm{mm} \\
\text { AFF: } 5.1(3.9-7) \mathrm{mm} \\
\text { b) PR A2: } \\
\text { Rest: } 1.7(1.4-2) \mathrm{mm} \\
\text { AFF: } 2.2(1.8-3) \mathrm{mm}\end{array}$ \\
\hline $\begin{array}{r}\text { Klauser } \\
\text { et al }^{11}\end{array}$ & $\begin{array}{l}34 \text { climbers } \\
\text { Control group } \\
\text { (20 nonclimbers) } \\
216 \text { fingers }\end{array}$ & $\begin{array}{l}\text { US } 10 \mathrm{MHz} \\
\text { (gel-pad) }\end{array}$ & $\begin{array}{l}\text { a) Rest } \\
\text { b) AFF (max): } \\
\text { MCP } 0^{\circ} \\
\text { PIP } 40^{\circ} \text { flex } \\
\text { DIP } 10^{\circ} \text { flex }\end{array}$ & & $\begin{array}{l}\text { a) CR A2: } \\
\text { Rest: } 3.1 \pm 0.05 \mathrm{~mm} \\
\text { AFF: } 5.1 \pm 0.15 \mathrm{~mm}\end{array}$ \\
\hline $\begin{array}{l}\text { Hauger } \\
\text { et }^{1}{ }^{12}\end{array}$ & 11 cadaver hands & $\begin{array}{l}\text { US } 12 \mathrm{MHz} \\
\text { CT } \\
\text { MRI }\end{array}$ & $\begin{array}{l}\text { a) Rest } \\
\text { b) Flex } \\
\text { c) AFF }(500 \mathrm{~g}) \text { : } \\
\text { fingers flex }\end{array}$ & $\begin{array}{l}\text { a) A2: } \\
\text { DT PP }\end{array}$ & $\begin{array}{l}\text { a) CR A2: } \\
\text { Rest: } 1.1(1-2) \mathrm{mm} \\
\text { Flex: } 2.4(2-4) \mathrm{mm} \\
\text { AFF: } 3.3(1-4) \mathrm{mm} \\
\text { b) PR A2: } \\
\text { Rest: } 0.5(0-1) \mathrm{mm} \\
\text { Flex: } 0.5(0-1) \mathrm{mm} \\
\text { AFF: } 1.4(0-2) \mathrm{mm}\end{array}$ \\
\hline $\begin{array}{r}\text { Klauser } \\
\text { et }^{13}{ }^{13}\end{array}$ & 64 climbers & $\begin{array}{l}\text { US } 12 \mathrm{MHz} \\
\text { (gel pad) } \\
\text { MRI }\end{array}$ & $\begin{array}{l}\text { a) Rest } \\
\text { b) AFF (max): } \\
\text { MCP } 0^{\circ} \\
\text { PIP } 40^{\circ} \text { flex } \\
\text { DIP } 10^{\circ} \text { flex }\end{array}$ & $\begin{array}{l}\text { a) A2: } \\
15-20 \mathrm{~mm} \\
\text { distal from } \\
\text { PP base } \\
\text { b) A4: } \\
\text { mid MP }\end{array}$ & $\begin{array}{l}\text { a) CR A2: } \\
\text { Rest: } 2.8 \pm 0.7(1.1-3.3) \mathrm{mm} \\
\text { AFF: } 4.6 \pm 0.6(3.0-4.9) \mathrm{mm} \\
\text { b) PR A2: } \\
\text { Rest: } 0.9 \pm 0.7(0-2.2) \mathrm{mm} \\
\text { AFF: } 1.5 \pm 0.6(1.0-3.1) \mathrm{mm} \\
\text { c) CR A4: } \\
\text { Rest: } 1.5 \pm 0.4(1.1-2.0) \mathrm{mm} \\
\text { AFF: } 3.1 \pm 0.5(2.5-3.7) \mathrm{mm}\end{array}$ \\
\hline $\begin{array}{l}\text { Schöffl } \\
\text { et al }^{14}\end{array}$ & 604 climbers & $\begin{array}{l}\text { US } 7.5 \mathrm{MHz} \\
\text { (water tube) } \\
\text { MRI optional }\end{array}$ & & & $\begin{array}{l}\text { a) CR A2: } \\
>2 \mathrm{~mm} \\
\text { b) PR A2: } \\
<2 \mathrm{~mm} \\
\text { c) CR A4: } \\
>2 \mathrm{~mm} \\
\text { d) PR A4: } \\
<2 \mathrm{~mm}\end{array}$ \\
\hline
\end{tabular}

AFF, active forced flexion; A2, annular pulley 2; A4, annular pulley 4; CR, complete rupture; CT, computerized tomography; DIP, distal interphalangeal joint; DT, distal third; ext, extension; flex, flexion; MRI, magnetic resonance imaging; MP, medial phalange; MCP, metacarpophalangeal joint; mid, midpoint; PR, partial rupture; PIP, proximal interphalangeal joint; PP, proximal phalange; PT, proximal third; US, ultrasound. 
Table 3. Critical Appraisal Skills Programme scores obtained for the descriptive studies reviewed

\begin{tabular}{|c|c|c|c|c|c|c|c|}
\hline Question & 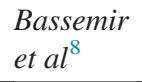 & $\begin{array}{l}\text { Schöffl } \\
\text { et al }\end{array}$ & $\begin{array}{l}\text { Bodner } \\
\text { et al }\end{array}$ & $\begin{array}{l}\text { Klauser } \\
\text { et al }^{11}\end{array}$ & $\begin{array}{l}\text { Hauger } \\
\text { et al }^{12}\end{array}$ & $\begin{array}{l}\text { Klauser } \\
\text { et al }^{13}\end{array}$ & $\begin{array}{l}\text { Schöffl } \\
\text { et al }^{14}\end{array}$ \\
\hline $\begin{array}{l}\text { 1. Is the comparison with a reference } \\
\text { technique adequate? }\end{array}$ & No & No & Yes & No & Yes & Yes & No \\
\hline 2. Is the spectrum of patients adequate? & Yes & Yes & Yes & Yes & Yes & Yes & Yes \\
\hline 3. Is the test adequately described? & Yes & No & Yes & Yes & No & Yes & No \\
\hline 4. Were the results assessed in a blinded fashion? & N/A & Yes & Yes & N/A & Yes & Yes & N/A \\
\hline $\begin{array}{l}\text { 5. Was the decision to use the gold standard } \\
\text { independent of the result? }\end{array}$ & Yes & Yes & Yes & Yes & Yes & Yes & Yes \\
\hline 6. May probability coefficients be calculated? & No & Yes & Yes & No & No & Yes & No \\
\hline 7. Were the results accurate? & Yes & Yes & Yes & Yes & Yes & Yes & Yes \\
\hline $\begin{array}{l}\text { 8. Were test reproducibility and interpretation } \\
\text { satisfactory? }\end{array}$ & Yes & Yes & Yes & Yes & Yes & Yes & No \\
\hline 9. Was the test acceptable? & Yes & Yes & Yes & Yes & Yes & Yes & Yes \\
\hline 10. Did the results modify the decision of how to act? & Yes & Yes & Yes & Yes & Yes & Yes & Yes \\
\hline Scientific quality score & $7 / 10$ & $8 / 10$ & $10 / 10$ & $7 / 10$ & $8 / 10$ & $10 / 10$ & $5 / 10$ \\
\hline
\end{tabular}

N/A, not applicable.

\section{US ASSESSMENT PROTOCOL}

The frequencies of the US transducers used ranged from $7.5^{14}$ to $18 \mathrm{MHz}{ }^{8}$ In 4 studies, ${ }^{10,12-14}$ MRI was also performed as a diagnostic test. Coupling agents also varied among the studies: silicon pad, ${ }^{10}$ gel pad, ${ }^{8,11,13}$ or water tube. ${ }^{14}$ In 2 studies,,${ }^{9,12}$ no coupling agent was specified in the methods section. None of the studies considered the benefits or drawbacks of the coupling agents used or performed comparisons.

In all studies reviewed, A4 pulley measurements were made over the midpoint of the middle phalanx. However, the landmark for measuring TBD for the A2 pulley varied.

Participant hand position during measurement was the most constant parameter across the studies. In 5 studies, resting position measurements with fingers extended were performed in addition to measurements in active forced flexion. ${ }^{8,10-13}$ However, the specific degrees of the different finger joints and degree of counter-resisted force applied was not homogeneous (Table 2).

\section{US TBD MEASUREMENTS}

TBD measurements were performed using only a long axis view in 4 studies ${ }^{8,9,11,13}$ and using both long and short axis views in 2 studies. ${ }^{10,12}$ This was not specified in 1 study. ${ }^{14}$

In all 7 studies reviewed, TBD reference values were provided. In cases of complete A2 pulley rupture, TBD varied from $1.9 \mathrm{~mm}^{9}$ to $5.1 \mathrm{~mm}^{10}$ when measured in active forced flexion. For complete A4 pulley rupture, TBD showed less variation, from $1.8 \mathrm{~mm}^{9}$ to $3.1 \mathrm{~mm}^{13}$ in active forced flexion (Table 2). A2 partial pulley rupture measurements were only performed in 4 of the 7 studies..$^{10,12-14}$ No study reported on partial A4 pulley rupture measurements.
TBD values for A2 partial pulley ruptures varied from 1.4 $\mathrm{mm}^{12}$ to $2.2 \mathrm{~mm}^{10}$

\section{Discussion}

This systematic review provides useful information about US assessment protocols for the diagnosis of injuries to the flexor annular pulleys A2 and A4. US is today considered the gold standard ${ }^{8,9}$ for a number of reasons. Among these, we should highlight the fact that A2 and A4 pulleys are the most frequently injured, their anatomical features are the most favorable for US technical assessment, ${ }^{8}$ and a comparative US and MRI study detected $98 \%$ sensitivity and $100 \%$ specificity for US. ${ }^{13}$

In a systematic review of pulley rupture diagnosis conducted in 2006, clinical bowstringing was the most cited diagnostic test, followed by MRI and US. This early review found 93 articles (keywords: rock climbing, A2 pulley, finger injury, or tendon injury); 35 were selected, yet only 2 focused on US. ${ }^{1}$ In the present review, we identified 3447 articles and finally selected for analysis 7 reports addressing US and TBD in A2 and A4 pulleys. Both articles of the earlier review ${ }^{1}$ were among the 7 selected for the present study. Recently, there has been an increase in the available evidence on US for diagnosis of pulley injuries. However, the number of articles considering TBD remains low.

Clear discrepancies emerged among the studies in terms of the US assessment protocols used, which could account for the variability in the minimum TBD used to define a ruptured A2 or A4 pulley.

\section{STUDY SAMPLE CHARACTERISTICS}

Two of the studies reviewed were performed on cadavers (mean age 75.5 and 73.5 [68-78] y, respectively). ${ }^{9,12}$ 
Cadaver tissue properties and ages varied from those of the in vivo US studies conducted in younger climbers. The most recently published study was performed on dissected fingers using a complex measurement system fixed to a wooden plate immersed in water so that biomechanical tests could be performed in addition to US assessment. ${ }^{9}$ Although in vitro study sample characteristics will always be biased compared to in vivo studies, they have the benefit of allowing pulley injuries to be simulated before measurements are taken. ${ }^{9}$

\section{US ASSESSMENT PROTOCOL}

US image quality is determined as much by transducer frequency as by the coupling agent used. This is illustrated by the different image resolution offered by the $7.5 \mathrm{MHz}$ instrument used in a water tube ${ }^{14}$ and the $18 \mathrm{MHz}$ linear probe using a gel pad. ${ }^{8}$ Many authors argue that to obtain reliable measurements, a minimum frequency of 10 to 12 $\mathrm{MHz}$ is required. However, in more recent reports, a minimum of $14 \mathrm{MHz}$ is recommended. ${ }^{8,9}$ As coupling agents, a gel or silicon pad may limit the flexion degree of the finger joints, ${ }^{8}, 10,11,13$ which could be avoided by using a water tube. ${ }^{14} \mathrm{~A}$ water tube also avoids direct contact between the transducer and skin, ensuring that the pressure of the transducer does not reduce TBD. None of the studies specified the use of conventional US gel, which is the most frequently used agent in clinical practice and has been suggested to be more suitable, at least for A3 pulley injuries, than the water tube. ${ }^{17}$

TBD measurement in active forced flexion seems to be the most reliable method ${ }^{13}$ due to its similarity to the mechanism of injury, which is more likely to occur in the crimp grip position. ${ }^{18,19}$ In 6 of the 7 studies reviewed here, this maneuver was used. ${ }^{8-13}$ However, if we consider the 6 studies in which the forced flexion finger position was described in detail, variations among the studies were detected in the degree of flexion of the metacarpophalangeal (MCP), proximal interphalangeal (PIP), and distal interphalangeal (DIP) joints. In 3 studies, the authors agreed that these joints should be flexed at $0^{\circ}, 40^{\circ}$, and $10^{\circ}$, respectively, ${ }^{10,11,13}$ whereas the authors of another study preferred $30^{\circ}$ of flexion for the DIP joint. ${ }^{9}$ In a further study, a combined position of complete extension of the MCP and PIP joints with $30^{\circ}$ flexion of the DIP joint was proposed. ${ }^{8}$

Because of the relatively large size of linear transducers, it is sometimes difficult to correctly position them, and this difficulty increases for greater interphalangeal joint flexion assessment positions. To avoid this problem, while maintaining a hand position as similar as possible to the crimp grip, the use of a stick transducer could be a better approach because it requires less space and provides higher image resolution. ${ }^{11}$
For accurate measurements of TBD, the degrees of each joint need to be defined in terms of each possible lesion. A2 and A4 pulley injuries often occur when climbers adopt a crimp grip position, whereby the PIP joint is flexed to 90 to $100^{\circ}$ and the DIP joint is hyperextended to 10 to $15^{\circ}$. The ideal situation would be to maintain this position using the US transducer. However, both the transducer size and the reduced area of contact of the transducer on the phalanx, especially at the proximal phalanx for the A2 pulley, make such measurements very difficult. The only study in which TBD was measured in a full crimp grip position was one in which MRI was the imaging technique used. $^{20}$

Another factor that varied among studies was the anatomical landmark used-in other words, the level of the phalanx over which TBD is measured. All reports concurred that for an A4 pulley, the landmark should be the midpoint of the middle phalanx. ${ }^{8,13}$ However, there were clear discrepancies across the studies focusing on the A2 pulley. These differences could perhaps be explained by the fact that the length, thickness, and location of the A2 pulley are more difficult to distinguish because of their close proximity to the A1 pulley. ${ }^{9}$ Thus, the landmarks mentioned by the different authors were the distal third of the proximal phalanx (locating it $15-20 \mathrm{~mm}$ distal to the base of the proximal phalanx), ${ }^{12,13}$ the distal end of the A2 pulley, ${ }^{10}$ and the medial-proximal third of the proximal phalanx. ${ }^{8}$ The midpoint of the proximal phalanx was also used as a landmark for A2 pulley TBD measurement in one of the studies excluded from our review. ${ }^{21}$ It is important to precisely define anatomical landmarks to avoid false positive or negative diagnoses.

Another source of conflict was the degree of force of flexor activation provided by the patient and the opposing resistance force provided by the therapist. As for finger position, there was no consensus regarding the optimal activation force in the studies reviewed. Three main methods were used to actively counter-resist the force flexion of the patient's finger to visualize separation of the flexor tendon from the phalanx. Some used a made-to-measure sling for the distal phalanx with a standard $500 \mathrm{~g}$ weight for its activation. ${ }^{8,12}$ A different and much simpler approach was for the radiologist to use his or her free hand to apply a counter-resisted force to the distal phalanx while instructing the patient to execute maximum flexion force of the finger. ${ }^{10,11}$ , 13 One study used levers to traction cadaver fingers, creating a passive flexion force of $10 \mathrm{~N} .{ }^{9}$ Thus, in addition to using different ways of forcing active flexion of the finger to be assessed, studies were inconsistent in the flexion force used (values ranged from $500 \mathrm{~g}$ [equivalent to $0.5 \mathrm{~N}$ ] to a maximum force that could be 100 times this value).

The method most resembling a measurement protocol was the distal phalanx sling method, although the weight 
or force applied should be adjusted according to the anthropometric and physiological characteristics of the patient and the patient's finger and sex rather than standardizing this weight at $500 \mathrm{~g}^{8,12}$ Before US assessment, the ideal would be to calculate for each patient the minimal, yet sufficient, force to be applied to separate the flexor tendon as much as possible. However, this forced position is often difficult to achieve in clinical practice because the pain produced by the lesion reduces the force that the patient can generate.

\section{US TBD MEASUREMENTS}

The final and perhaps most important matter of debate was the definition of the minimum TBD used to diagnose a complete or partial rupture of the A2 or A4 annular pulleys. As previously discussed, methodological procedures varied widely, and this should be kept in mind when comparing TBD values.

For complete A2 pulley ruptures, TBD values in active forced flexion position varied from $1.9^{9} \mathrm{~mm}$ to $5.1 \mathrm{~mm}^{10}$ $(3.2 \mathrm{~mm}$ ); for complete A4 rupture, values ranged from $1.8 \mathrm{~mm}^{9}$ to $3.1 \mathrm{~mm}^{13}$ (1.3 mm difference). In resting finger position, TBD values varied from $1.1 \mathrm{~mm}^{12}$ to $3.1 \mathrm{~mm}^{10}$ (1 $\mathrm{mm}$ difference) for complete $\mathrm{A} 2$ rupture and from 1.5 $\mathrm{mm}^{13}$ to $2 \mathrm{~mm}^{14}$ ( $0.5 \mathrm{~mm}$ difference) for complete A4 rupture. It is obvious that results for the A4 pulley in both finger positions are less discrepant than for A2. However, it seems that the criterion of $2 \mathrm{~mm}$ as a threshold for the diagnosis of both complete A2 and A4 pulley ruptures is the most widely accepted. ${ }^{14,22}$

For partial A2 pulley ruptures, minimum TBD values varied from $1.4 \mathrm{~mm}^{12}$ to $2.2 \mathrm{~mm}^{10}$ ( $0.8 \mathrm{~mm}$ difference) in active forced flexion position and from $0.5 \mathrm{~mm}^{12}$ to $1.7 \mathrm{~mm}^{10}(1.2$ $\mathrm{mm}$ difference) in resting finger position in 3 out of the 7 studies that also analyzed this type of rupture. ${ }^{10,12,13}$ The small number of articles available prevents drawing any firm conclusions. More specifically designed studies are needed to better understand TBD in partial A2 pulley ruptures.

A3 pulley ruptures and combined ruptures such as A2/ $\mathrm{A} 3$ or $\mathrm{A} 3 / \mathrm{A} 4$ were not considered in this review due to a low sensitivity of US for TBD measurement $(<50-76 \%){ }^{9,17}$ Combined A2/A3/A4 pulley ruptures also were not considered because, although their US TBD values have shown high sensitivity $(90 \%),{ }^{9}$ their diagnosis is essentially clinical, being based on tendon bowstringing.

\section{Conclusions}

The findings of our systematic review indicate that, although compelling evidence exists regarding the reliability of US for the diagnosis of A2 and A4 pulley injuries, reference TBD values cannot be extracted from the literature there is too much variability in the US assessment protocols used.

Several points of discrepancy will need to be resolved in future studies, including US measurement protocols, transducer frequencies, and coupling agents, which give rise to differences in image resolution. Furthermore, the optimal flexion angles required for MCP, PIP, and DIP joints and the US pulley measurement landmarks have not been well established. Finally, in further work, the optimal force and counter-resistance that the patient and examiner should apply will also need to be defined.

Author Contributions: Designed the study and conducted the literature search (XIU, ESRL, JDLF); literature selection (XIU, ESRL, AOPV, $\mathrm{AOC}, \mathrm{PB}$ ); data analysis and interpretation (JDLF, MB, XIU); writing the manuscript (XIU, ESRL, MB, JDLF). All authors were responsible for drafting the manuscript and have read and approved the final version. Financial/Material Support: None.

Disclosures: None.

\section{References}

1. El-Sheikh Y, Wong I, Farrokhyar F, Thoma A. Diagnosis of finger flexor pulley injury in rock climbers: a systematic review. Can J Plast Surg. 2006;14(4):227-31.

2. Schreiber T, Allenspach P, Seifert B, Schweizer A. Connective tissue adaptations in the fingers of performance sport climbers. Eur J Sport Sci. 2015;15(8):696-702.

3. Lutter C, Hotfiel T, Tischer T, Lenz R, Schöffl V. Evaluation of rock climbing related injuries in older athletes. Wilderness Environ Med. 2019;30(4):362-8.

4. Spanish Sports Council. Available at: https://www.csd.gob. es/es/federaciones-y-asociaciones/federaciones-deportivasespanolas/licencias. Accessed June 10, 2020.

5. King EA, Lien JR. Flexor tendon pulley injuries in rock climbers. Hand Clin. 2017:33(1):141-8.

6. Schöffl I, Oppelt K, Jüngert J, Schweizer A, Bayer T, Neuhuber W, et al. The influence of concentric and eccentric loading on the finger pulley system. J Biomech. 2009;42(13): 2124-8.

7. Crowley TP. The flexor tendon pulley system and rock climbing. J Hand Microsurg. 2012;4(1):25-9.

8. Bassemir D, Unglaub F, Hahn P, Müller LP, Bruckner T, Spies CK. Sonographical parameters of the finger pulley system in healthy adults. Arch Orthop Trauma Surg. 2015;135(11):1615-22.

9. Schöffl I, Hugel A, Schoffl V, Rascher W, Jüngert J. Diagnosis of complex pulley ruptures using ultrasound in cadaver models. Ultrasound Med Biol. 2017;43(3):662-9.

10. Bodner G, Rudisch A, Gabl M, Judmaier W, Springer P, Klauser A. Diagnosis of digital flexor tendon annular pulley disruption: comparison of high frequency ultrasound and MRI. Ultraschall Med. 1999;20(4):131-6.

11. Klauser A, Bodner G, Frauscher F, Gabl M, Zur Nedden D. Finger injuries in extreme rock climbers. Assessment of high- 
resolution ultrasonography. Am J Sports Med. 1999;27(6): 733-7.

12. Hauger O, Chung CB, Lektrakul N, Botte MJ, Trudell D, Boutin RD, et al. Pulley system in the fingers: normal anatomy and simulated lesions in cadavers at MR imaging, CT, and US with and without contrast material distension of the tendon sheath. Radiology. 2000;217(1):201-12.

13. Klauser A, Frauscher F, Bodner G, Halpern EJ, Schocke MF, Springer P, et al. Finger pulley injuries in extreme rock climbers: depiction with dynamic US. Radiology. 2002;222(3): 755-61.

14. Schöffl V, Hochholzer T, Winkelmann HP, Strecker W. Pulley injuries in rock climbers. Wilderness Environ Med. 2003;14(2):94-100.

15. Moher D, Liberati A, Tetzlaff J, Altman DG. Preferred reporting items for systematic reviews and meta-analyses: the PRISMA statement. PLoS Med. 2009;6(7):e1000097.

16. Lijmer JG, Mol BW, Heisterkamp S, Bonsel GJ, Prins MH, van der Meulen JH, et al. Empirical evidence of design-related bias in studies of diagnostic tests. JAMA. 1999;282(11): 1061-6.

17. Schöffl I, Deeg J, Lutter C, Bayer T, Schöffl V. Diagnosis of A3 pulley injuries using ultrasound. Sportverletz Sportschaden. 2018;32(4):251-9.

18. Schweizer A, Hudek R. Kinetics of crimp and slope grip in rock climbing. J Appl Biomech. 2011;27(2):116-21.

19. Schöffl I, Oppelt K, Jüngert J, Schweizer A, Neuhuber W, Schöffl V. The influence of the crimp and slope grip position on the finger pulley system. $J$ Biomech. 2009;42(13):2183-7.

20. Hoff MN, Greenberg TD. MRI sport-specific pulley imaging. Skeletal Radiol. 2018;47(7):989-92.

21. Schöffl VR, Einwag F, Strecker W, Schöffl I. Strength measurement and clinical outcome after pulley ruptures in climbers. Med Sci Sports Exerc. 2006;38(4):637-43.

22. Schöffl VR, Schöffl I. Injuries to the finger flexor pulley system in rock climbers: current concepts. J Hand Surg Am. 2006;31(4):647-54. 